\title{
BMJ Open Alcohol-related harm to others in England: a cross-sectional analysis of national survey data
}

\author{
Caryl Beynon, ${ }^{1}$ David Bayliss, ${ }^{1}$ Jenny Mason, ${ }^{1}$ Kate Sweeney, ${ }^{1}$ Clare Perkins, ${ }^{1}$ \\ Clive Henn ${ }^{2}$
}

To cite: Beynon C, Bayliss D, Mason J, et al. Alcohol-related harm to others in England: a cross-sectional analysis of national survey data. BMJ Open 2019;9:e021046. doi:10.1136/ bmjopen-2017-021046

- Prepublication history and additional material for this paper are available online. To view these files, please visit the journal online (http://dx.doi. org/10.1136/bmjopen-2017021046).

Received 7 December 2017 Revised 3 October 2018 Accepted 14 November 2018

Check for updates

(c) Author(s) (or their employer(s)) 2019. Re-use permitted under CC BY-NC. No commercial re-use. See rights and permissions. Published by BMJ.

${ }^{1}$ Risk Factors Intelligence Team, Public Health England, Liverpool, UK

${ }^{2}$ Alcohol, Drugs and Tobacco Division, Public Health England, London, UK

Correspondence to

Dr Caryl Beynon;

caryl.beynon@phe.gov.uk

\section{ABSTRACT}

Objectives To estimate the prevalence, the frequency and the perpetrators of alcohol-related harm to others (AHTO) and identify factors associated with experiencing harm and aggressive harm.

Design Cross-sectional survey.

Setting England.

Participants Adults (general population) aged 16 and over. Outcome measures Percentage of respondents who experienced harm. Socioeconomic and demographic factors associated with the outcomes. Outcomes were (1) experienced harm/did not experience harm and (2) experienced aggressive harm (physically threatened, physically hurt and forced/pressured into something sexual)/ did not experience an aggressive harm (no aggressive harm plus no harm at all).

Results Data to support a response rate calculation were not collected; $96.3 \%$ of people surveyed completed the AHTO questions. The weighted sample was $4874 ; 20.1 \%$ (95\% Cl 18.9 to 21.4, $\mathrm{N}=980$ ) reported experiencing harm in the previous 12 months and $4.6 \%(95 \% \mathrm{Cl} 4.0$ to $5.4, \mathrm{~N}=225$ ) reported experiencing an aggressive harm. Friends and strangers were the dominant perpetrators. Most harms (74.8\%) occurred less than monthly. Factors associated with experiencing harm were: younger age $(p<0.001)$, drinking harmfully/hazardously $(p<0.001)$, white British $(p<0.001$ compared to other white groups and Asian groups and $p=0.017$ compared to black groups), having a disability $(p<0.001)$, being educated $(p<0.001$ compared to no education) and living in private rented accommodation ( $p=0.004$ compared with owned outright). Being in the family stage of life (defined as having children in the household) had significantly lower odds of harm ( $p=0.006$ compared to being single), as did being retired ( $p<0.001$ compared to being employed). Factors associated with experiencing an aggressive harm were similar.

Conclusions This exploratory study, using data collected through the Alcohol Toolkit Survey, shows that AHTO affects $20.1 \%$ of the population of England. Even apparently minor harms, like being kept awake, can have a negative impact on health, while aggressive harms are clearly of concern. Using a standard methodology to measure harm across studies would be advantageous. Policies that focus on alcohol must take into consideration the impact of drinking on those other than the drinker.

\section{Strengths and limitations of this study}

This is the largest survey on alcohol-related harm to others in the UK and the first national survey in England.

- The sampling approach and weighting ensured the data were representative of the population of England.

- There is potential selection bias which is inherent in all national surveys.

- The use of a bespoke survey made comparison of the findings with the literature difficult but when the study was initiated, no other universally accepted survey was identified.

\section{INTRODUCTION}

The detrimental effects of alcohol are well documented; in 2012 alcohol consumption was responsible for approximately $6 \%$ of deaths and $5 \%$ of disease burden globally. ${ }^{1}$ The focus has been on the harmful effects of alcohol on the drinker with less attention on the harms caused to others, including families, work colleagues and wider society. The WHO's global alcohol strategy highlights the need to consider the harm alcohol causes to people other than the drinker, ${ }^{2}$ and it is these alcohol-related harms to others (AHTO) that are the focus of this study.

Health and social data provide insight into the potential harms caused by another's drinking. Data from the Crime Survey for England and Wales, for example, show that in just over half of all violent crimes the victim perceived the offender to be under the influence of alcohol and that drinking was particularly implicated in violent incidents between strangers. ${ }^{3}$ Data from the Department of Transport show that in England during 20132015, there were almost 10000 alcohol-related road traffic accidents in which at least one driver failed the alcohol breathalyser test (data are available at: https://fingertips. phe.org.uk/profile/local-alcohol-profiles), 
demonstrating a considerable potential harm to both the drinking driver and to others on the roads.

In the last decade or so, several studies have aimed to quantify and explore AHTO in more detail. These studies have provided widely varying estimates of the prevalence of harm, largely due to differences in the way harms are defined and the reference population. Studies which focus on identifying the sociodemographic and behavioural factors associated with being the victim of harm do not always provide consistent findings, suggesting the need for further research. While there is a relatively consistent finding across studies that younger age increases the likelihood of experiencing harm, ${ }^{4-6}$ the association of harm with other characteristics is less clear. For example, women have generally been identified as more at risk of harm from another's drinking than men but this is not consistent across all countries and some authors report this association for certain types of harm only. ${ }^{4-7}$ Two studies identified that women were more likely to experience unwanted sexual attention/harassment/assault, whereas men were more likely to experience having their belongings or property damaged. ${ }^{46}$

When the impact of alcohol includes the effects to the individual drinker and wider society, the cost is considerable. A review of studies in high-income countries found the gross economic costs of alcohol to range from $1.4 \%$ to $2.7 \%$ of gross domestic product; in the UK in 2016, this would be equivalent to between £27 billion and $£ 52$ billion. ${ }^{8}$ There is a need to better understand AHTO and the characteristics of those affected in order to implement an effective response. To date there has been no national survey of AHTO in England, although surveys have been conducted in Scotland, ${ }^{9}$ Wales ${ }^{10}$ and Ireland. ${ }^{11}$ The objectives of this exploratory study were to estimate the prevalence of AHTO in England, identify factors associated with being the victim of harm, the frequency with which this harm occurs and the perpetrators of harm.

\section{METHOD}

\section{The survey}

The questions to identify experience of AHTO were devised after an evidence review and were added to the Alcohol Toolkit Survey (ATS) between 1 November 2015 and 31 January 2016. The ATS is a cross-sectional household survey, run by University College London and administered by Ipsos MORI using computer-assisted interviews. Each month, a new sample of adults aged 16 and over who live in England complete the survey. Households are selected using a type of random location sampling which is a hybrid of random probability sampling and simple quota sampling (so that each monthly sample is representative of the population). Interviews are conducted with one member of the selected household. ${ }^{12}$ The AHTO questions were self-completed following guidance on this from the Research Support and Governance Office, Public Health England. Due to the novel and exploratory nature of the work, no formal sample size calculation was undertaken as the parameters on which to base this were unknown. Instead, a 3-month window of data collection was chosen, knowing that the ATS aimed to survey approximately 1800 adults per month. ${ }^{12}$ The sample size was considerably larger than other studies of AHTO conducted in the UK. ${ }^{91013}$

The AHTO questions asked whether or not the respondent had experienced the following harms from another's drinking in the past 12 months:

Because of someone else's drinking, I have...

1. Had a serious argument that did not include physical violence.

2. Felt physically threatened.

3. Been emotionally hurt or neglected.

4. Been physically hurt due to them assaulting me or acting violently.

5. Been physically hurt due to them accidentally injuring me (eg, by falling on me).

6. Been put at risk in a car when someone was driving after drinking.

7. Felt forced or pressured into sex or something sexual.

8. Felt uncomfortable or anxious at a social occasion (eg, a party).

9. Had someone break or damage something that mattered to me.

10. Had money that would have improved the quality of my life spent on their alcohol-related purchases.

11. Felt genuinely concerned that they may cause harm to my children or someone else's children.

12. Had to spend my personal time caring for a person with a long-term health condition or disability that resulted from their current or previous drinking.

13. Been let down by someone due to them failing to do something that I was counting on them to do because of their drinking.

14. Been kept awake due to noise or disruption.

15. Drank alcohol myself in order to cope with the problems caused by their drinking.

16. Had to stop seeing or being in contact with someone because of their drinking.

17. Had to move out of my usual place of residence and stay somewhere else.

18. Had contact with the police.

If a respondent indicated that they had experienced any of the harms they were asked to indicate who perpetrated the harm and the frequency with which the harm occurred. Response options for who perpetrated the harm were: someone you were in a relationship with (eg, wife/ husband, partner) who you lived with, someone you were in a relationship with (eg, wife/husband, partner) who you did not live with, another family member you lived with, a family member you did not live with, someone else you lived with, a friend, a work colleague, someone else you know, a stranger, refused/prefer not to say and don't know. Response options for the frequency of harm were: daily or almost daily (ie, 4-7 days per week), weekly (ie, 1-3 times per week), monthly (ie, 2-3 times per month), less than once a month, refused/prefer not to say and 
don't know. For each of the 18 harms, people were able to select more than one perpetrator category. Respondents were able to select only one frequency per harm. The frequency of harm could therefore include harm caused by more than one perpetrator. In some instances, people who reported a harm did not report who perpetrated this or how frequently the harm occurred.

A range of demographic and socioeconomic variables, collected as part of the ATS, were used as independent variables: sex (female, male), age band in years (16-24, 25-44, 45-64, 65 and over), broad ethnic group (white British, other white, black, Asian, other), life stage (single, prefamily, family, postfamily), educational attainment (no qualifications, General Certificate of Secondary Education (GCSE)/O-level/General Certificate of Education (CSE), A-level/vocational, degree/higher degree, other/ still studying), social grade (AB (higher managerial, administrative and professional), C1 (supervisory, clerical and junior managerial, administrative and professional), C2 (skilled manual workers), D (semiskilled and unskilled manual workers), E (state pensioners, casual and lowest grade workers, unemployed with state benefits only)), tenure of home (owned outright, bought on a mortgage, rented from local authority, rented from private landlord, other), self-defined disability (yes, no) and employment status (employed, unemployed, economically inactive, retired). 'Life stage' was derived from age, marital status and number of children living in the household and is defined as follows: single (up to the age of 39, not married/in a civil partnership and no children in the household), prefamily (up to the age of 39 , married/in a civil partnership and no children in the household), family (children living in the household) and postfamily (aged 40 and over, no children in the household). The respondents' alcohol consumption was measured using the Alcohol Use Disorders Identification Test (AUDIT) which is used to identify hazardous and harmful drinkers. Here, hazardous/harmful drinkers were identified as those with scores of 8 or more if aged 65 or under, and scores of 7 or more if aged over 65 , in line with WHO guidance. $^{14}$

\section{Analysis}

Respondents who refused to complete the AHTO questions and those who chose the 'don't know' or 'refused/ prefer not to say' options for all 18 harm questions were excluded from all analyses. $\chi^{2}$ tests were used to compare the characteristics of those who were included in the analysis to those that were excluded due to missing data on the AHTO questions. Individuals who failed to provide a valid response to other questions were excluded from the analysis of that particular independent variable. People with one or more missing covariate were excluded from the multivariate analyses.

Two binary dependent variables were created. 'Any harm' was coded as yes if a person had experienced any of the 18 harm types in the previous 12 months. 'Aggressive harm' was coded as yes if the person had experienced one or more of the following three harms: felt physically threatened, been physically hurt due to them assaulting me or acting violently and felt forced or pressured into sex or something sexual. The categorisation of 'aggressive harm' is in line with previous research on AHTO. ${ }^{4}$

All analyses were undertaken using Stata V.13 and the 'svy' command prefix for analysing survey data. Prevalence was estimated by dividing the positive responses by the total responses for each harm type, any harm and aggressive harm; 95\% CI were calculated for each prevalence estimate using the standard settings of Stata's 'svy: tabulate' command. ${ }^{15}$ Bivariate independence was tested using a 'corrected' Pearson $\chi^{2}$ statistic for survey data (design-based $F$ tests based on Rao and Scott correction) ${ }^{16}$ Multivariate analyses (binary logistic regression) were conducted to model the joint effects of the independent variables significantly associated with any harm and aggressive harm in the bivariate analyses with 'no harm' and 'no aggressive harm' as the reference categories. Adjusted ORs (AOR) are presented in comparison to the reference category for the given variable and $t$ tests provide an indication of statistical significance. Where comparisons are presented between categories of a variable where neither is the reference category, an indication of statistical significance is given using adjusted Wald tests. Analyses were weighted (using weights generated by the ATS) in order to improve the representativeness of the sample relative to an English population profile using multiple sociodemographic variables. ${ }^{12}$ Analysis using weighted data results in small discrepancies in some totals and percentages due to rounding. For example, sample sizes were rounded to whole numbers because they represent people, but the percentages were calculated using unrounded values. Due to the exploratory nature of the analysis, $\alpha$ was set at 0.05 for all tests. The risk of type I error is considered less important than the risk of type II error: deflating $\alpha$ may limit further investigation at a point where the evidence base is developing.

\section{Patient and public involvement}

Patients and the public were not involved in this study.

\section{RESULTS}

\section{Missing data}

The original (unweighted) sample size was 5068. The proportion of missing data was relatively small; 96 people $(1.9 \%)$ did not complete the AHTO questions and a further $91(1.8 \%)$ answered 'don't know/refused' to all AHTO questions; both groups were excluded from the analyses leaving an unweighted sample size of 4881 (96.3\% of the original sample). Online supplementary table 1 compares the number/proportion of people included in the analyses with those who were excluded because they did not provide a response to the AHTO questions, by independent variable. There were significant differences for four variables in the proportion of people that were excluded: sex $(3.1 \%$ of females and 
Table 1 Prevalence of harm in the previous 12 months, weighted data

\begin{tabular}{|c|c|c|c|}
\hline Harm type & $\begin{array}{l}\text { Number of } \\
\text { respondents who } \\
\text { experienced harm }\end{array}$ & $\begin{array}{l}\text { Percentage of } \\
\text { respondents who } \\
\text { experienced harm }\end{array}$ & $95 \% \mathrm{Cl}$ \\
\hline Been kept awake due to noise or disruption & 390 & 8.0 & 7.2 to 8.9 \\
\hline Felt uncomfortable or anxious at a social occasion (eg, a party) & 331 & 6.8 & 6.0 to 7.6 \\
\hline Had a serious argument that did NOT include physical violence & 275 & 5.7 & 5.0 to 6.4 \\
\hline $\begin{array}{l}\text { Been let down by someone due to them failing to do something that } \\
\text { I was counting on them to do because of their drinking }\end{array}$ & 174 & 3.6 & 3.0 to 4.2 \\
\hline Been emotionally hurt or neglected & 170 & 3.5 & 3.0 to 4.1 \\
\hline Felt physically threatened & 164 & 3.4 & 2.8 to 4.0 \\
\hline $\begin{array}{l}\text { Had to stop seeing or being in contact with someone because of } \\
\text { their drinking }\end{array}$ & 120 & 2.5 & 2.0 to 3.0 \\
\hline Had to contact the police & 117 & 2.4 & 2.0 to 2.9 \\
\hline Had someone break or damage something that mattered to me & 95 & 1.9 & 1.5 to 2.5 \\
\hline Been physically hurt due to them assaulting me or acting violently & 92 & 1.9 & 1.5 to 2.4 \\
\hline Been put at risk in a car when someone was driving after drinking & 75 & 1.5 & 1.2 to 2.0 \\
\hline $\begin{array}{l}\text { Felt genuinely concerned that they may cause harm to my children } \\
\text { or someone else's children }\end{array}$ & 61 & 1.2 & 0.9 to 1.6 \\
\hline $\begin{array}{l}\text { Had to spend my personal time caring for a person with a long- } \\
\text { term health condition or disability that resulted from their current or } \\
\text { previous drinking }\end{array}$ & 57 & 1.2 & 0.9 to 1.5 \\
\hline $\begin{array}{l}\text { Been physically hurt due to them accidentally injuring me (eg, by } \\
\text { falling on me) }\end{array}$ & 53 & 1.1 & 0.8 to 1.5 \\
\hline $\begin{array}{l}\text { Had money that would have improved the quality of my life spent on } \\
\text { their alcohol-related purchases }\end{array}$ & 50 & 1.0 & 0.8 to 1.4 \\
\hline $\begin{array}{l}\text { Drank alcohol myself in order to cope with the problems caused by } \\
\text { their drinking }\end{array}$ & 33 & 0.7 & 0.5 to 1.0 \\
\hline Felt forced or pressured into sex or something sexual & 33 & 0.7 & 0.5 to 1.0 \\
\hline $\begin{array}{l}\text { Had to move out of my usual place of residence and stay } \\
\text { somewhere else }\end{array}$ & 25 & 0.5 & 0.3 to 0.8 \\
\hline At least one reported harm & 980 & 20.1 & 18.9 to 21.4 \\
\hline At least one aggressive harm & 225 & 4.6 & 4.0 to 5.4 \\
\hline
\end{tabular}

Weighted $n=4874$.

$4.3 \%$ of males, $\mathrm{p}=0.023)$, tenure of home $(2.5 \%$ of people who owned their own home outright, $4.6 \%$ of people who bought their home on a mortgage, $4.5 \%$ of people who rented from a local authority, $3.0 \%$ who rented from a private landlord and $6.4 \%$ of 'other', $\mathrm{p}<0.001$ ), disability $(5.6 \%$ of people who considered themselves as disabled and $3.2 \%$ of people who did not, $\mathrm{p}=0.002$ ) and AUDIT score $(3.3 \%$ of non-hazardous/harmful drinkers and $5.5 \%$ of hazardous/harmful drinkers, $\mathrm{p}=0.003$ ). Of the 4881 people included in the bivariate analyses, 189 $(3.9 \%)$ were excluded from the multivariate analyses because one or more independent variable was missing.

\section{Prevalence of harm}

Table 1 reports the estimated prevalence of each type of harm. In total 980 people $(20.1 \%$, 95\% CI $18.9 \%$-21.4\%) reported experiencing at least one harm due to someone else's drinking in the past 12 months. These data by sex are reported in online supplementary table 2 . While the numbers are too small to make a comprehensive assessment of the differences by sex (and such differences are not the focus of this paper), some disparities in harm were evident. For example, there was a clear difference between the proportion of men $(2.1 \%, 95 \%$ CI $1.6 \%$ to $2.9 \%)$ and women $(4.8 \%, 95 \%$ CI $3.9 \%$ to $5.8 \%)$ who reported experiencing alcohol-related emotional hurt or neglect. Aggressive harms were experienced by 225 people $(4.6 \%, 95 \%$ CI $4.0 \%-5.4 \%)$.

\section{Bivariate and multivariate results (factors associated with harm)}

Factors associated with experiencing any harm in the bivariate analyses are reported in table 2. Experience of harm decreased with age. This trend by age was reflected in experience of harm by life stage, with $36.5 \%$ $(95 \%$ CI $32.8 \%$ to $40.5 \%, \mathrm{~N}=251)$ of single people 
Table 2 Bivariate and multivariate comparisons of harm versus no harm from another's drinking in past 12 months, weighted data

\begin{tabular}{|c|c|c|c|c|c|c|c|c|c|}
\hline \multirow[b]{3}{*}{ Independent variable } & \multicolumn{6}{|c|}{ Bivariate comparisons } & & & \\
\hline & \multicolumn{3}{|c|}{ No harm } & \multicolumn{3}{|c|}{ Harm } & \multicolumn{3}{|c|}{ Multivariate comparisons } \\
\hline & $\mathbf{N}$ & $\%$ & $95 \% \mathrm{Cl}$ & $\mathbf{N}$ & $\%$ & $95 \% \mathrm{Cl}$ & AOR & $P$ value & $95 \% \mathrm{Cl}$ \\
\hline \multicolumn{10}{|l|}{ Sex } \\
\hline Female & 2008 & 80.1 & 78.3 to 81.8 & 498 & 19.9 & 18.2 to 21.7 & \multirow{2}{*}{\multicolumn{3}{|c|}{ Not entered into the model }} \\
\hline Male & 1887 & 79.7 & 77.7 to 81.4 & 482 & 20.3 & 18.6 to 22.3 & & & \\
\hline \multicolumn{10}{|l|}{ Age band* } \\
\hline $16-24$ & 446 & 63.4 & 59.6 to 67.0 & 258 & 36.6 & 33.0 to 40.4 & \multicolumn{3}{|c|}{ Reference } \\
\hline $25-44$ & 1278 & 78.4 & 76.0 to 80.7 & 352 & 21.6 & 19.3 to 24.0 & 0.63 & $<0.001$ & 0.49 to 0.83 \\
\hline $45-64$ & 1237 & 81.5 & 79.1 to 83.7 & 281 & 18.5 & 16.3 to 20.9 & 0.50 & $<0.001$ & 0.34 to 0.75 \\
\hline $65+$ & 933 & 91.2 & 89.3 to 92.9 & 90 & 8.8 & 7.1 to 10.7 & 0.36 & $<0.001$ & 0.21 to 0.61 \\
\hline \multicolumn{10}{|l|}{ Broad ethnic group* } \\
\hline White British & 2975 & 78.2 & 76.7 to 79.7 & 830 & 21.8 & 20.3 to 23.4 & \multicolumn{3}{|c|}{ Reference } \\
\hline Other white groups & 334 & 84.9 & 80.4 to 88.5 & 59 & 15.1 & 11.5 to 19.6 & 0.52 & $<0.001$ & 0.36 to 0.76 \\
\hline Black groups & 151 & 83.9 & 78.6 to 88.1 & 29 & 16.1 & 11.9 to 21.4 & 0.61 & 0.017 & 0.41 to 0.92 \\
\hline Asian groups & 376 & 89.1 & 85.8 to 91.8 & 46 & 10.9 & 8.2 to 14.2 & 0.39 & $<0.001$ & 0.28 to 0.56 \\
\hline Other groups & 44 & 82.2 & 68.7 to 90.7 & 9 & 17.8 & 9.3 to 31.3 & 0.60 & 0.154 & 0.30 to 1.21 \\
\hline \multicolumn{10}{|l|}{ Life stage $^{\star}$} \\
\hline Single & 436 & 63.5 & 59.5 to 67.2 & 251 & 36.5 & 32.8 to 40.5 & \multicolumn{3}{|c|}{ Reference } \\
\hline Prefamily & 222 & 72.2 & 65.6 to 77.9 & 86 & 27.8 & 22.1 to 34.4 & 0.91 & 0.620 & 0.61 to 1.34 \\
\hline Family & 1285 & 81.1 & 78.8 to 83.2 & 299 & 18.9 & 16.8 to 21.2 & 0.68 & 0.006 & 0.52 to 0.89 \\
\hline Postfamily & 1950 & 85.0 & 83.3 to 86.6 & 344 & 15.0 & 13.4 to 16.7 & 0.85 & 0.433 & 0.56 to 1.28 \\
\hline \multicolumn{10}{|l|}{ Education* } \\
\hline No qualifications & 683 & 90.1 & 87.5 to 92.2 & 75 & 9.9 & 7.8 to 12.5 & \multicolumn{3}{|c|}{ Reference } \\
\hline GCSE/O-level/CSE & 764 & 79.3 & 76.2 to 82.1 & 199 & 20.7 & 17.9 to 23.8 & 1.74 & $<0.001$ & 1.25 to 2.44 \\
\hline A-level/vocational & 974 & 73.3 & 70.7 to 75.9 & 354 & 26.7 & 24.1 to 29.3 & 2.04 & $<0.001$ & 1.48 to 2.82 \\
\hline Degree/higher degree & 1156 & 79.3 & 76.8 to 81.7 & 301 & 20.7 & 18.3 to 23.2 & 2.16 & $<0.001$ & 1.56 to 3.00 \\
\hline Other/still studying & 294 & 85.6 & 81.2 to 89.1 & 50 & 14.4 & 10.9 to 18.9 & 1.42 & 0.109 & 0.92 to 2.18 \\
\hline \multicolumn{10}{|l|}{ Social grade $†$} \\
\hline $\mathrm{AB}$ & 1066 & 80.8 & 78.0 to 83.3 & 254 & 19.2 & 16.7 to 22.0 & \multirow{5}{*}{\multicolumn{3}{|c|}{ Not entered into the model }} \\
\hline $\mathrm{C} 1$ & 1023 & 77.4 & 75.0 to 79.6 & 299 & 22.6 & 20.4 to 25.0 & & & \\
\hline $\mathrm{C} 2$ & 878 & 81.7 & 78.8 to 84.4 & 196 & 18.3 & 15.6 to 21.2 & & & \\
\hline $\mathrm{D}$ & 614 & 82.5 & 79.1 to 85.4 & 131 & 17.5 & 14.6 to 20.9 & & & \\
\hline E & 313 & 75.8 & 71.8 to 79.4 & 100 & 24.2 & 20.6 to 28.2 & & & \\
\hline \multicolumn{10}{|l|}{ Tenure* } \\
\hline Owned outright & 1451 & 86.0 & 84.0 to 87.8 & 237 & 14.0 & 12.3 to 16.0 & \multicolumn{3}{|c|}{ Reference } \\
\hline Bought on a mortgage & 1142 & 79.2 & 76.4 to 81.6 & 301 & 20.9 & 18.4 to 23.6 & 0.97 & 0.825 & 0.74 to 1.28 \\
\hline $\begin{array}{l}\text { Rented from local } \\
\text { authority }\end{array}$ & 341 & 78.8 & 74.6 to 82.5 & 92 & 21.2 & 17.6 to 25.4 & 1.38 & 0.060 & 0.99 to 1.94 \\
\hline $\begin{array}{l}\text { Rented from private } \\
\text { landlord }\end{array}$ & 678 & 70.1 & 66.9 to 73.1 & 289 & 29.9 & 26.9 to 33.1 & 1.52 & 0.004 & 1.15 to 2.01 \\
\hline Other & 248 & 81.1 & 76.7 to 84.8 & 58 & 19.0 & 15.2 to 23.4 & 1.11 & 0.562 & 0.77 to 1.61 \\
\hline \multicolumn{10}{|l|}{ Disability* } \\
\hline Considers self disabled & 396 & 76.0 & 71.9 to 79.7 & 125 & 24.0 & 20.3 to 28.1 & \multicolumn{3}{|c|}{ Reference } \\
\hline Not disabled & 3422 & 80.3 & 78.9 to 81.6 & 842 & 19.7 & 18.4 to 21.1 & 0.56 & $<0.001$ & 0.42 to 0.74 \\
\hline
\end{tabular}


Table 2 Continued

\begin{tabular}{|c|c|c|c|c|c|c|c|c|c|}
\hline \multirow[b]{3}{*}{ Independent variable } & \multicolumn{6}{|c|}{ Bivariate comparisons } & & & \\
\hline & \multicolumn{3}{|c|}{ No harm } & \multicolumn{3}{|c|}{ Harm } & \multicolumn{3}{|c|}{ Multivariate comparisons } \\
\hline & $\mathbf{N}$ & $\%$ & $95 \% \mathrm{Cl}$ & $\mathbf{N}$ & $\%$ & $95 \% \mathrm{Cl}$ & AOR & $P$ value & $95 \% \mathrm{Cl}$ \\
\hline \multicolumn{10}{|l|}{ Employment status* } \\
\hline Employed & 2081 & 78.0 & 76.0 to 79.8 & 588 & 22.0 & 20.2 to 24.0 & \multicolumn{3}{|c|}{ Reference } \\
\hline Unemployed & 157 & 73.2 & 66.4 to 79.0 & 58 & 26.8 & 21.0 to 33.6 & 1.09 & 0.648 & 0.75 to 1.58 \\
\hline Economically inactive & 634 & 73.2 & 70.1 to 76.1 & 232 & 26.8 & 24.0 to 29.9 & 1.01 & 0.896 & 0.81 to 1.27 \\
\hline Retired & 1021 & 90.9 & 89.1 to 92.5 & 102 & 9.1 & 7.5 to 10.9 & 0.54 & $<0.001$ & 0.38 to 0.78 \\
\hline \multicolumn{10}{|l|}{ AUDIT* } \\
\hline $\begin{array}{l}\text { Not hazardous/harmful } \\
\text { drinking }\end{array}$ & 3463 & 82.7 & 81.4 to 84.0 & 723 & 17.3 & 16.0 to 18.6 & \multicolumn{3}{|c|}{ Reference } \\
\hline Hazardous/harmful drinking & 419 & 62.1 & 57.9 to 66.1 & 256 & 37.9 & 33.9 to 42.1 & 2.06 & $<0.001$ & 1.66 to 2.56 \\
\hline \multicolumn{10}{|c|}{$\begin{array}{l}\text { Weighted } n=4874 \text { (bivariate analyses) and } 4698 \text { (multivariate analysis). Bivariate totals that are } 4875 \text { not } 4874 \text { are due to } \\
\text { rounding as the analyses use weighted data. } \\
\text { *Test of bivariate independence indicates significant difference }(p<0.05) \text {. } \\
\dagger A B \text { is higher managerial, administrative and professional and intermediate managerial, administrative and professional; } C 1 \\
\text { is supervisory, clerical and junior managerial, administrative and professional; } C 2 \text { is skilled manual workers; } D \text { is semiskilled } \\
\text { and unskilled manual workers; and E is state pensioners, casual and lowest grade workers, unemployed with state benefits } \\
\text { only. } \\
\text { AOR, adjusted OR; AUDIT, Alcohol Use Disorders Identification Test. }\end{array}$} \\
\hline
\end{tabular}

experiencing harm compared with $15.0 \%$ (95\% CI 13.4\% to $16.7 \% \mathrm{~N}=344$ ) of those in a postfamily life stage. White British people were more likely to report experiencing harm $(21.8 \%, 95 \% \mathrm{CI} 20.3 \%$ to $23.4 \% \mathrm{~N}=830$ ) than people of other broad ethnic groups; people of Asian ethnicity had the lowest prevalence $(10.9 \%, 95 \%$ CI $8.2 \%$ to $14.2 \% \mathrm{~N}=46$ ). People with no qualifications were least likely to report experiencing harm $(9.9 \%, 95 \%$ CI $7.8 \%$ to $12.5 \% \mathrm{~N}=75$ ). Those whose highest attainment was A-level or vocational had the highest prevalence $(26.7 \%, 95 \% \mathrm{CI}$ $24.1 \%$ to $29.3 \% \mathrm{~N}=354$ ). People in the private-rented sector had the highest harm prevalence by tenure $(29.9 \%$, $95 \%$ CI $26.9 \%$ to $33.1 \% \mathrm{~N}=289$ ). This compares to just $14.0 \%$ (95\% CI $12.3 \%$ to $16.0 \% \mathrm{~N}=237$ ) of people who owned their home outright experiencing harm. People who considered themselves disabled were more likely to report having experienced harm than those who did not $(24.0 \%, 95 \%$ CI $20.3 \%$ to $28.1 \%, \mathrm{~N}=125$ compared with $19.7 \%, 95 \%$ CI $18.4 \%$ to $21.1 \% \mathrm{~N}=842$ ). Those who were unemployed $(26.8 \%, 95 \%$ CI $21.0 \%$ to $33.6 \% \mathrm{~N}=58)$ or economically inactive $(26.8 \%, 95 \%$ CI $24.0 \%$ to 29.9\% $\mathrm{N}=232$ ) were more likely to report harm than those who were employed $(22.0 \%, 95 \%$ CI $20.2 \%$ to $24.0 \% \mathrm{~N}=588$ ); the difference between the unemployed and employed was not significant. Retired people were much less likely to report experiencing at least one harm $(9.1 \%, 95 \%$ CI $7.5 \%$ to $10.9 \% \mathrm{~N}=102)$ than people across all other employment statuses. The prevalence of AHTO was significantly higher among hazardous/ harmful drinkers $(37.9 \%, 95 \%$ CI $33.9 \%$ to $42.1 \% \mathrm{~N}=256)$ compared with those who were not $(17.3 \%, 95 \%$ CI $16.0 \%$ to $18.6 \% \mathrm{~N}=723$ ).
In the multivariate model, young age remained strongly associated with experiencing harm due to someone else's drinking, with those aged 16-24 having greater odds of experiencing harm than all older age groups (table 2). Being a hazardous/harmful drinker was strongly associated with experiencing harm; the odds of experiencing harm were around double the odds of those who were not hazardous/harmful drinkers. Being white British compared with being other white, black or Asian ethnicities was also associated with greater odds of experiencing harm, as was considering oneself disabled, being educated and living in private-rented accommodation compared with being an owning outright. The odds of experiencing harm were lower for respondents in the family stage of life than the odds for those that were single. The odds of experiencing harm were lower for retired respondents than the odds for employed respondents.

\section{Aggressive harm}

In bivariate analyses, men were marginally more likely to experience an aggressive harm than women $(5.3 \%$ and $4.0 \%$ respectively, $\mathrm{p}=0.04$, table 3 ). The other characteristics associated with experiencing aggressive harms were similar to experiencing any harm, with a higher prevalence of aggressive harm associated with being younger, disabled, single, non-retired, white British, renting accommodation and being a hazardous/harmful drinker.

Controlling for other variables in the model, sex and stage of life were not associated with experiencing an aggressive harm (table 3). Age remained associated with harm after adjustment for other variables; those aged 45 and over had lower odds of experiencing an aggressive 
Table 3 Bivariate and multivariate comparisons of aggressive harm versus no aggressive harm from another's drinking in past 12 months, weighted data

\begin{tabular}{|c|c|c|c|c|c|c|c|c|c|}
\hline \multirow[b]{3}{*}{ Independent variable } & \multicolumn{6}{|c|}{ Bivariate comparisons } & & & \\
\hline & \multicolumn{3}{|c|}{ No aggressive harm } & \multicolumn{3}{|c|}{ Aggressive harm } & \multicolumn{3}{|c|}{ Multivariate comparisons } \\
\hline & $\mathbf{N}$ & $\%$ & $95 \% \mathrm{Cl}$ & $\mathbf{N}$ & $\%$ & $95 \% \mathrm{Cl}$ & AOR & $P$ value & $95 \% \mathrm{Cl}$ \\
\hline \multicolumn{10}{|l|}{ Sex* } \\
\hline Male & 2242 & 94.7 & 93.5 to 95.6 & 127 & 5.3 & 4.4 to 6.5 & \multicolumn{3}{|c|}{ Reference } \\
\hline Female & 2407 & 96.1 & 95.1 to 96.8 & 99 & 4.0 & 3.2 to 4.9 & 0.74 & 0.086 & 0.53 to 1.04 \\
\hline \multicolumn{10}{|l|}{ Age band* } \\
\hline $16-24$ & 646 & 91.7 & 89.1 to 93.6 & 59 & 8.4 & 6.4 to 10.9 & \multicolumn{3}{|c|}{ Reference } \\
\hline $25-44$ & 1539 & 94.4 & 92.9 to 95.6 & 91 & 5.6 & 4.4 to 7.1 & 0.84 & 0.510 & 0.49 to 1.43 \\
\hline $45-64$ & 1454 & 95.8 & 94.4 to 96.9 & 64 & 4.2 & 3.1 to 5.6 & 0.43 & 0.024 & 0.20 to 0.89 \\
\hline $65+$ & 1010 & 98.8 & 98.0 to 99.3 & 12 & 1.2 & 0.7 to 2.0 & 0.29 & 0.044 & 0.09 to 0.97 \\
\hline \multicolumn{10}{|l|}{ Broad ethnic group* } \\
\hline White British & 3605 & 94.8 & 93.8 to 95.5 & 200 & 5.3 & 4.5 to 6.2 & \multicolumn{3}{|c|}{ Reference } \\
\hline Other white groups & 384 & 97.7 & 95.6 to 98.8 & 9 & 2.3 & 1.2 to 4.4 & 0.30 & 0.002 & 0.14 to 0.64 \\
\hline Black groups & 176 & 97.6 & 95.1 to 98.8 & 4 & 2.4 & 1.2 to 4.9 & 0.37 & 0.020 & 0.16 to 0.86 \\
\hline Asian groups & 411 & 97.5 & 95.4 to 98.7 & 11 & 2.5 & 1.4 to 4.7 & 0.43 & 0.023 & 0.21 to 0.89 \\
\hline Other groups & 52 & 97.5 & 88.7 to 99.5 & 1 & 2.5 & 0.5 to 11.3 & 0.36 & 0.217 & 0.07 to 1.83 \\
\hline \multicolumn{10}{|l|}{ Life stage ${ }^{\star}$} \\
\hline Single & 629 & 91.5 & 88.9 to 93.6 & 58 & 8.5 & 6.4 to 11.1 & \multicolumn{3}{|c|}{ Reference } \\
\hline Prefamily & 286 & 92.9 & 88.2 to 95.9 & 22 & 7.1 & 4.2 to 11.8 & 1.23 & 0.573 & 0.60 to 2.50 \\
\hline Family & 1519 & 95.9 & 94.7 to 96.9 & 65 & 4.1 & 3.1 to 5.3 & 0.89 & 0.684 & 0.52 to 1.55 \\
\hline Postfamily & 2213 & 96.5 & 95.5 to 97.3 & 81 & 3.5 & 2.7 to 4.6 & 1.80 & 0.097 & 0.90 to 3.60 \\
\hline \multicolumn{10}{|l|}{ Education* } \\
\hline No qualifications & 739 & 97.5 & 96.0 to 98.4 & 19 & 2.6 & 1.6 to 4.0 & \multicolumn{3}{|c|}{ Reference } \\
\hline GCSE/O-level/CSE & 911 & 94.6 & 92.6 to 96.1 & 52 & 5.4 & 3.9 to 7.4 & 1.75 & 0.069 & 0.96 to 3.21 \\
\hline A-level/vocational & 1242 & 93.6 & 91.9 to 94.9 & 86 & 6.5 & 5.1 to 8.1 & 1.69 & 0.077 & 0.95 to 3.01 \\
\hline Degree/higher degree & 1396 & 95.8 & 94.3 to 96.9 & 62 & 4.2 & 3.1 to 5.7 & 1.94 & 0.042 & 1.02 to 3.69 \\
\hline Other/still studying & 337 & 97.9 & 95.8 to 99.0 & 7 & 2.1 & 1.0 to 4.2 & 0.88 & 0.788 & 0.36 to 2.16 \\
\hline \multicolumn{10}{|l|}{ Social grade $†$} \\
\hline$A B$ & 1265 & 95.9 & 94.2 to 97.1 & 54 & 4.1 & 2.9 to 5.8 & \multirow{5}{*}{\multicolumn{3}{|c|}{ Not entered into the model }} \\
\hline C1 & 1267 & 95.8 & 94.6 to 96.8 & 55 & 4.2 & 3.2 to 5.4 & & & \\
\hline $\mathrm{C} 2$ & 1016 & 94.6 & 92.5 to 96.0 & 59 & 5.5 & 4.0 to 7.5 & & & \\
\hline $\mathrm{D}$ & 718 & 96.4 & 94.5 to 97.6 & 27 & 3.6 & 2.4 to 5.5 & & & \\
\hline E & 382 & 92.6 & 89.8 to 94.7 & 30 & 7.4 & 5.3 to 10.2 & & & \\
\hline \multicolumn{10}{|l|}{ Tenure* } \\
\hline Owned outright & 1648 & 97.7 & 96.7 to 98.3 & 40 & 2.4 & 1.7 to 3.3 & \multicolumn{3}{|c|}{ Reference } \\
\hline Bought on a mortgage & 1386 & 96.0 & 94.5 to 97.2 & 57 & 4.0 & 2.8 to 5.5 & 1.03 & 0.918 & 0.57 to 1.88 \\
\hline Rented from local authority & 405 & 93.5 & 90.4 to 95.6 & 28 & 6.5 & 4.4 to 9.6 & 2.58 & 0.006 & 1.31 to 5.09 \\
\hline $\begin{array}{l}\text { Rented from private } \\
\text { landlord }\end{array}$ & 885 & 91.5 & 89.3 to 93.3 & 82 & 8.5 & 6.7 to 10.7 & 2.33 & 0.003 & 1.34 to 4.05 \\
\hline Other & 287 & 94.0 & 91.0 to 96.0 & 18 & 6.0 & 4.0 to 9.0 & 2.04 & 0.039 & 1.04 to 4.02 \\
\hline \multicolumn{10}{|l|}{ Disability* } \\
\hline Considers self disabled & 477 & 91.4 & 88.4 to 93.7 & 45 & 8.6 & 6.3 to 11.7 & \multicolumn{3}{|c|}{ Reference } \\
\hline Not disabled & 4086 & 95.8 & 95.1 to 96.5 & 178 & 4.2 & 3.5 to 4.9 & 0.37 & $<0.001$ & 0.24 to 0.59 \\
\hline Employment status* & & & & & & & & & \\
\hline
\end{tabular}

Continued 
Table 3 Continued

\begin{tabular}{|c|c|c|c|c|c|c|c|c|c|}
\hline \multirow[b]{3}{*}{ Independent variable } & \multicolumn{6}{|c|}{ Bivariate comparisons } & & & \\
\hline & \multicolumn{3}{|c|}{ No aggressive harm } & \multicolumn{3}{|c|}{ Aggressive harm } & \multicolumn{3}{|c|}{ Multivariate comparisons } \\
\hline & $\mathbf{N}$ & $\%$ & $95 \% \mathrm{Cl}$ & $\mathbf{N}$ & $\%$ & $95 \% \mathrm{Cl}$ & AOR & $P$ value & $95 \% \mathrm{Cl}$ \\
\hline Employed & 2535 & 95.0 & 93.8 to 95.9 & 135 & 5.0 & 4.1 to 6.2 & \multicolumn{3}{|c|}{ Reference } \\
\hline Unemployed & 204 & 95.0 & 91.3 to 97.2 & 11 & 5.0 & 2.8 to 8.7 & 0.62 & 0.166 & 0.32 to 1.22 \\
\hline Economically inactive & 799 & 92.2 & 90.2 to 93.9 & 67 & 7.8 & 6.1 to 9.8 & 1.10 & 0.654 & 0.73 to 1.66 \\
\hline Retired & 1110 & 98.9 & 98.1 to 99.3 & 13 & 1.1 & 0.7 to 1.9 & 0.33 & 0.018 & 0.13 to 0.83 \\
\hline \multicolumn{10}{|l|}{ AUDIT* } \\
\hline $\begin{array}{l}\text { Not hazardous/harmful } \\
\text { drinking }\end{array}$ & 4038 & 96.5 & 95.7 to 97.1 & 149 & 3.6 & 2.9 to 4.3 & \multicolumn{3}{|c|}{ Reference } \\
\hline Hazardous/harmful drinking & 599 & 88.7 & 85.6 to 91.2 & 76 & 11.3 & 8.8 to 14.4 & 2.35 & $<0.001$ & 1.63 to 3.40 \\
\hline
\end{tabular}

Weighted $n=4874$ (bivariate analyses) and 4698 (multivariate analysis). Bivariate totals that are 4875 not 4874 are due to rounding as the analyses use weighted data.

${ }^{*}$ Test of bivariate independence indicates significant difference $(p<0.05)$.

$† A B$ is higher managerial, administrative and professional and intermediate managerial, administrative and professional; $C 1$ is supervisory, clerical and junior managerial, administrative and professional; C2 is skilled manual workers; D is semiskilled and unskilled manual workers; and $E$ is state pensioners, casual and lowest grade workers, unemployed with state benefits only.

AOR, adjusted OR; AUDIT, Alcohol Use Disorders Identification Test.

harm than those aged 16-24. Disability was also strongly associated with experience of aggressive harm; the odds of experiencing aggressive harm for non-disabled people was just over a third of the odds for disabled people (AOR $=0.37,95 \%$ CI 0.24 to 0.59 ). Housing tenure was relatively strongly associated, with the odds of experiencing an aggressive harm for renters around double the odds of those who are home owners. This was also the case for hazardous/harmful drinkers, with an AOR of 2.35 (95\% CI 1.63 to 3.40 ) relative to those who were not hazardous/harmful drinkers. Being white British compared with being in the other white, black or Asian ethnic groups was also associated with greater odds of experiencing an aggressive harm. Differences in the odds of experiencing an aggressive harm between people with different educational attainment were minimal; the only significant difference being the greater odds for those with a degree/higher degree relative to those with no qualifications. The odds of experiencing an aggressive harm for those that were retired remained significantly lower than the odds of an aggressive harm for those that were employed (AOR $0.33,95 \%$ CI 0.13 to 0.83 ).

\section{Perpetrators of harm}

Respondents could select more than one perpetrator category per harm type. Overall, the most frequently reported perpetrators of harms were friends $(23.4 \%$ of total perpetrator reports $\mathrm{N}=590)$ and strangers $(22.9 \%$ of total perpetrator reports, $\mathrm{N}=578$ ), while work colleagues were the least reported perpetrators $(3.7 \%$, of total perpetrator reports, $\mathrm{N}=94$, figure 1$)$. The perpetrator varied according to the type of harm (online supplementary table 3 ). Focussing on the most common harms experienced, being kept awake due to noise or disruption was predominantly perpetrated by strangers $(49.5 \%, 95 \%$ CI $43.8 \%$ to $55.3 \%$; of the 370 people who were kept awake at night,

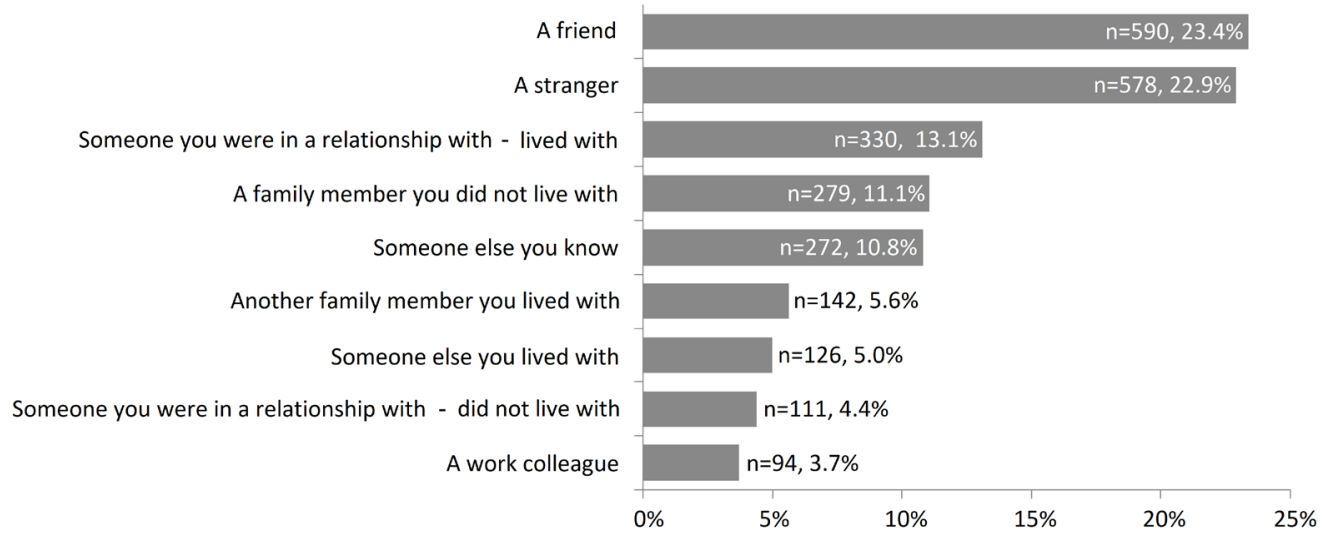

Figure 1 Perpetrators as a percentage of all reported harms to others, weighted data, weighted $n=2522$ (represents the total number of perpetrators across all harms). 


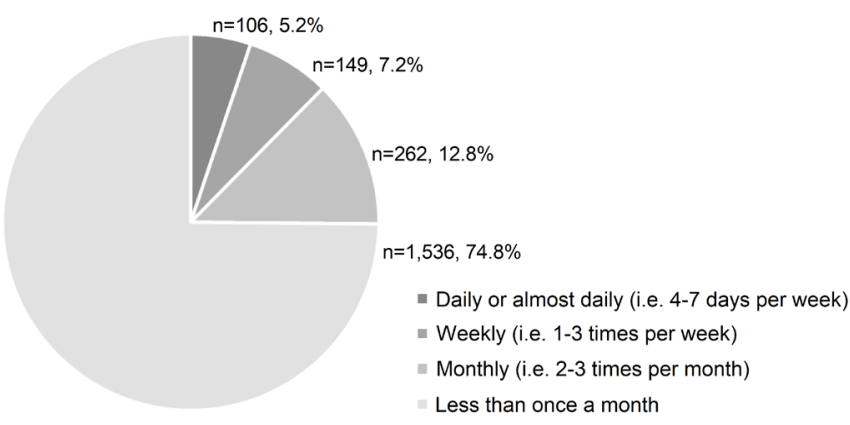

Figure 2 Frequency of all reported harms to others, weighted data, weighted $n=2052$ (represents the total number of harms across all individuals).

183 indicated a stranger perpetrated this harm), while both strangers and friends were the most common cause of feeling uncomfortable or anxious at a social occasion (strangers $34.4 \%, 95 \%$ CI $28.5 \%$ to $40.7 \%$; $\mathrm{N}=105 / 305$ friends $32.8 \%$, 95\% CI $27.2 \%$ to $39.0 \% \mathrm{~N}=100 / 305$ ). Serious arguments that did not include physical violence were predominantly perpetrated by friends (35.7\%, $95 \%$ CI $29.5 \%$ to $42.6 \% \mathrm{~N}=93 / 260$ ) or someone the respondent was in a relationship with and lived with (23.1\%, 95\% CI $17.6 \%$ to $29.6 \% \mathrm{~N}=60 / 259)$. Likewise, being let down by someone or being emotionally hurt or neglected were harm types perpetrated by people close to respondents.

Strangers were most likely to be the perpetrators of two of the aggressive harms: of the 154 respondents who reported being physically threatened, 93 indicated a stranger perpetrated this harm $(60.5 \%, 95 \%$ CI $51.2 \%-$ to $69.1 \%$ ). Of the 83 people who reported being physically hurt, 26 said a stranger perpetrated this harm (31.5\%, $95 \%$ CI $21.5 \%$ to $43.6 \%$ ). While $19.0 \%$ (95\% CI $6.5 \%$ to $44.2 \%, \mathrm{~N}=5 / 27)$ of respondents who reported being forced or pressured into sex or something sexual reported the perpetrator was a stranger, the most commonly reported perpetrator for this sexually aggressive harm was someone the respondent was in a relationship with and lived with $(23.3 \%, 95 \%$ CI $9.8 \%$ to $46.0 \%$, $\mathrm{N}=6 / 27$; rising to $39.9 \%$ when also including people in a relationship who lived elsewhere).

\section{Frequency of harm}

Figure 2 reports information on the frequency with which harms were experienced. The majority of reported harms were experienced less than once a month $(\mathrm{N}=1536,74.8 \%) ; 12.8 \%(\mathrm{~N}=262)$ of harms were experienced at least monthly but less than weekly, $7.2 \%(\mathrm{~N}=149)$ of harms were experienced weekly but less than daily and $5.2 \%(\mathrm{~N}=106)$ of harms were experienced daily or almost daily.

The frequency of harm varied by harm type (online supplementary table 4 ). The harm types reported to reoccur most often were those for which the description implies that the harm occurred over a prolonged period of time with someone whom the respondent was in regular contact. These included 'had to spend my personal time caring for a person with a long-term health condition or disability that resulted from their current or previous drinking' (19.4\% of people [10/53] who reported experiencing this harm did so daily or almost daily, $95 \%$ CI $10.2 \%$ to $33.8 \%$ ) and 'had to stop seeing or being in contact with someone because of their drinking' (19.3\% of people [21/107] who reported experiencing this harm did so daily or almost daily, $95 \%$ CI $11.9 \%$ to $29.6 \%$ ). It was less common for other harms to be experienced at a daily or almost daily frequency. Nevertheless, all harm types had at least one respondent reporting daily or almost daily frequency of harm.

\section{DISCUSSION}

In this exploratory study, one in five respondents experienced AHTO in the previous 12 months. The most commonly reported AHTO were being kept awake due to noise or disruption and feeling uncomfortable or anxious at a social occasion which have been identified as the most prevalent harms in other studies. ${ }^{45}$ More concerning, $4.6 \%$ reported experiencing an aggressive harm. Experiencing AHTO was associated with a number of demographic and socioeconomic variables. Friends and strangers were the dominant perpetrators of AHTO. Most harms occurred less than monthly but some harms were experienced daily or almost daily.

The main strength of this study is its large sample size; this is the largest survey on AHTO conducted in the UK and the first to provide data for England. The sampling and weighting strategy employed ensured the sample was representative of the English population and thus the generalisability of the findings. There are a number of limitations to note. Recall is always a problem with surveys; harms that occurred a year ago or had little impact on the respondent may be more difficult to recall. Attributing causality is not possible using a cross-sectional design. There are also some social groups that are systematically missing from surveys such as homeless people, those in hospital or care homes and those in prison; populations whose alcohol use is likely to be different. ${ }^{17}$ Previous studies on AHTO have also largely relied on cross-sectional surveys and are affected by the same limitations. A response rate could not be calculated because Ipsos MORI did not collect the necessary data. While the total amount of missing data is small, any missing data can potentially introduce bias. There were some significant differences in the characteristics of those that answered the AHTO questions and those that did not. The internal validity of the AHTO questions used here has not been measured; in the initial search of the literature the authors failed to identify a validated survey. Consequently, it is possible that discrepancies exist between the responses provided by participants and their actual experience of alcohol-related harm. Finally, ecological fallacy, where the inferences about individuals are made based on data for a group, is also a consideration in this type of study. It is 
likely that systematic differences exist in harm by population subgroups (eg, by sex and ethnicity) and future work on AHTO in the UK should explore this. It is possible that the findings on factors associated with harm represent those that are associated with the most common but 'low impact' harms and cannot be generalised to more severe harms. However, the fact that we specifically examine factors associated with aggressive harms (which are the most serious harms considered) mitigates this. That said, further research to identify the factors associated with individual harms would be advantageous.

In this study, the prevalence of harm was $20.1 \%$. The closest comparison is from a cross-sectional survey conducted in Wales in 2015 which used identical AHTO questions and reported the prevalence of any harm in the previous 12 months to be $59.7 \% .^{10}$ There is some evidence from routine data to support a lower prevalence of harm in England than Wales. For example, the percentage of violent incidents where the victim believed the offender(s) to be under the influence of alcohol tends to be higher in Wales than England ${ }^{18}$ although not conclusively so. However, the magnitude of the difference in the reported prevalence of harm between England and Wales seems questionable, given the similarities between the two nations. This difference could be due, in part, to differences in methodology and caution needs to be applied in drawing direct comparisons. In Wales, a free text box was included that gave participants the option to report 'other alcohol-related harm', and these were included in the 'any harm' figures for Wales which would likely increase the prevalence compared with England. This approach was not undertaken in England because not all harms reported in the free text box appeared to be alcohol- related, while others appeared to repeat harms already included within the 18 specific AHTO questions. In England, the harm questions were asked after the ATS questions; this may have affected how people perceived harm, and therefore how they responded to the harm questions. It is also possible that respondents were experiencing fatigue by the end of the survey and this may have affected how fully they reported their experiences of harm. The English survey was administered face-to-face while the survey in Wales was administered via the telephone using landline numbers. Using data from the USA, researchers comparing face-to-face and telephone interviews reported that telephone surveys may miss certain sections of the population if they solely rely on landlines, including those with lower incomes. ${ }^{19}$ However, the Welsh survey was weighted so the data were representative of the deprivation of the general population. ${ }^{10}$ Other surveys of AHTO conducted in the UK have reported the prevalence of harm in adults to be $28 \%$ in Ireland, ${ }^{11} 51 \%$ in Scotland, ${ }^{9} 79 \%$ in the North West of England, ${ }^{13}$ however these studies used very different AHTO questions so the results are not comparable. Despite the difference in prevalence between the Welsh survey and the current study, the relative prevalence of the types of harm were similar; being kept awake at night, feeling uncomfortable or anxious at a social occasion and having a serious argument were the most prevalent harms in both surveys.

Being a hazardous/harmful drinker increased the odds of experiencing AHTO. This is perhaps unsurprising given that drinking with other drinkers and in places where alcohol is consumed increases one's exposure to drinkers. However, the association with drinking and experiencing alcohol-harm is not conclusive. A cross-sectional comparison of harm from 'heavy drinking' friends and family across five Nordic countries and Scotland reported that drinking frequency was not significantly related to experiencing harm from others but binge drinking frequency was. A higher frequency of binge drinking increased the risk of experiencing AHTO in Sweden and Norway, and there was some evidence for this relationship in Finland also, but not in the other countries. ${ }^{7}$ A paper using the same Norwegian data showed that the association between experiencing harm, and one's own drinking was not evident for all types of harm. ${ }^{6}$ Other cross-sectional surveys show an association between one's own drinking and experience of any harm, ${ }^{20}{ }^{21}$ including two which report a dose response relationship, with dependent/ frequent risky drinkers having the greatest risk. ${ }^{42}$

Here, age was also associated with experiencing any harm and aggressive harm. A number of studies from a range of countries have reported that being of younger age increases the risk of being harmed from another's drinking. ${ }^{4-7} 23$ However, 'younger age' in this context does not always mean 'young'; one study, for example, concluded that those aged 59 or less had a higher risk of being negatively affected by a known drinker than those aged 60 and over. ${ }^{7}$ A global survey of 63725 respondents aged 18-34 years reported that those aged 18-24 years were significantly more likely to experience an aggressive AHTO than those aged $30-34$ or $25-29^{4}$; similar to results reported here.

The respondent's sex was not significantly associated with experiencing harm. The literature is mixed regarding sex as a risk factor. Women were reported to be significantly more likely to experience harm than men in Finland and Sweden but not in Denmark, Iceland, Norway or Scotland. ${ }^{56}$ Being a woman was found to be a significant risk factor for all harms and aggressive harms using data from the Global Drug Survey. ${ }^{4}$ The association of sex and experiencing harm is different for different types of harm. For example, women are significantly more likely than men to experience unwanted sexual attention/sexual harassment or assault, ${ }^{46}$ whereas men are more likely to have clothing, property or other belongings damaged. ${ }^{46}$ Survey data from the USA examined family/marriage, financial and assault harms due to drinking of a partner/spouse/family member and reported that women were more likely to report financial and family/martial harms while a higher proportion of men experienced assaults. ${ }^{24}$ While examining differences in harm by sex was not the focus of this study, online supplementary table 2 shows that such differences may exist. For example, there is a clear difference between 
the proportion of men $(2.1 \%, 95 \%$ CI $1.6 \%$ to $2.9 \%)$ and women $(4.8 \%, 95 \%$ CI $3.9 \%$ to $5.8 \%)$ who reported experiencing alcohol-related emotional hurt or neglect. Such differences should be considered in future work on this topic in the UK.

Few studies have considered whether ethnic background is a risk factor for experiencing harm. Data from the USA demonstrate that the link between ethnicity and experience of harm is not conclusive (two studies show no association and one a weak association). ${ }^{20} 2324$ Here, being white British was significantly associated with experiencing harm and also aggressive harm. Most minority ethnic groups in the UK have higher rates of abstinence from alcohol and lower levels of drinking than people of white ethnicity. ${ }^{25}$ However, the results of the multivariate modelling presented in this study show that white British ethnicity is associated with experiencing harm and aggressive harm independently of AUDIT score.

Having a disability was also significantly associated with experiencing any harm and an aggressive harm. No previous studies on the association between having a disability and experiencing alcohol-related harm were identified. However, there is good evidence to show that those with a disability are the victims of harm more generally including physical, sexual and intimate partner violence, ${ }^{26} 27$ and financial hardship. ${ }^{28}$

Being in the family stage of life also lowered the odds of experiencing harm compared with being single. This is perhaps surprising given that the survey included questions which specifically asked about harms most likely caused by a family member. Evidence on the effect of relationships and household types is mixed and largely dependent on the way these are categorised and so cannot be directly compared.

Educational attainment, type of accommodation, social grade and employment status are proxy measures for socioeconomic status. Literature on the effect of socioeconomic status is mixed, and comparisons are hindered by the multitude of different measures used in different studies. In this study, social grade was not significantly associated with harm or aggressive harm in the bivariate analyses. A study in Scotland also reported no significant difference in experience of any harm according to social class. $^{9}$

Here, findings show that experiencing harm was significantly associated with having qualifications (compared with having none) with the greatest odds being for those with a degree or higher degree. The association between education and experience of harm in the literature is mixed. Data from two national surveys (Denmark ${ }^{29}$ and the $\mathrm{USA}^{20}$ ) showed no clear association between experiencing harm and education level. Data from the Global Drug Survey showed no association between education and experience of harm or aggressive harm but there was an association between education and experiencing particular types of harm. ${ }^{4}$ However, a comparison of northern European countries reported that a significantly higher proportion of respondents with high school/university education experienced harm than those with elementary education in four of the six countries considered. ${ }^{5}$ Those with higher educational attainment were more likely to experience any harm in a Canadian study. ${ }^{30}$

The current study shows that being retired lowers the odds of experiencing harm and aggressive harm compared with all other employment statuses. This association was independent of age. The odds of being harmed did not differ significantly between those who were employed and not employed. A cross-sectional survey in Canada also reported that those who were retired were least likely to experience harm. ${ }^{30}$ Data from two surveys conducted in the USA show that those who were unemployed were significantly more likely to experience AHTO than those who were employed. ${ }^{23}{ }^{24}$ Data from Denmark show that employment might be significantly associated with experiencing harm but no conclusive results were provided, and the wide CIs show that estimates lacked precision. ${ }^{29}$ Conversely, data from the USA reported no association between experiencing any harm and employment status. ${ }^{20}$

Here, compared with those that owned their home outright, those who rented from a private landlord had significantly greater odds of experiencing harm and those who rented from the local authority or rented from a private landlord had significantly greater odds of experiencing an aggressive harm. No previous studies on the association between type of accommodation tenure and experiencing alcohol-related harm were identified. It is possible that those who rent represent a more transitory, poor and vulnerable population which increases their risk of harm. Research not specifically related to alcohol shows that those living in unstable housing (eg, living on the streets, in temporary sheltered accommodation or with relatives or friends) experience relatively high rates of victimisation, ${ }^{31} 32$ while data from national surveys in Great Britain show that being the victim of domestic property crimes is higher among those who rent (including those in the private-rented sector) than those who own their own homes. ${ }^{33}$

How exactly socioeconomic status influences the experience of harm is not clear from our findings. Neither social grade nor employment status (excepting retirement) were associated with AHTO in our study. Education, as a proxy of earning potential, was associated with AHTO, but there was no significant variation between the groups GCSE/O-level/CSE, A-level/vocational and degree/higher degree. No clear picture of the association between experience of harm and socioeconomic status emerges from the literature either. A comparable study of AHTO in Wales reported no association between experience of any harm and area-level deprivation..$^{10}$ It is possible that more sensitive methods are needed to fully explore the relationship between socioeconomic status and AHTO, and any patterns in relation to particular types of harm.

In the UK, there are cultural differences in drinking behaviour, and some of these are reflected in our AHTO findings (such as differences between ethnic groups). ${ }^{34}$ 
However, other sociocultural variations are not easily identified in our findings. For example, while national survey data show that people have different drinking habits across income levels (people on higher incomes tend to drink more ${ }^{34}$ ), this pattern is not reflected in our findings on socioeconomic status.

This study identified friends and strangers as the dominant perpetrators making up around $46 \%$ of all reports, though the perpetrator varied depending on type of harm. For example, family members made up a larger proportion of perpetrators of harms such as stopping seeing someone or having to care for someone because of their drinking. While three-quarters of harms were experienced less than monthly, $5.2 \%$ were experienced daily or almost daily indicating a considerable burden of alcohol-related harm for a section of the population. The frequency of experiencing harm was largely dependent on the type of harm. Harms with the highest frequency of daily/almost daily reports were those which occurred over a prolonged period of time and/or implied frequent contact with the perpetrator such as caring for someone with a long-term health condition or disability that results from them drinking. Data from two surveys suggest that exposure to heavy drinkers is associated with poorer health, well-being and quality of life. ${ }^{3738}$

To conclude, this is the largest ever survey of AHTO conducted within the UK and the first national study in England. It is clear that AHTO is relatively prevalent and that some individuals experience harm frequently. The most prevalent harms could be considered trivial but even apparently minor harms such as sleep disruption can have an impact on health and quality of life, ${ }^{39}$ particularly if experienced persistently. It is difficult to compare results with the literature because of the diversity of methods being employed. In order to support temporal and geographical comparisons, it would be advantageous for studies to use a consistent methodology including the sampling and data collection methods, in addition to the harm questions. The WHO ThaiHealth project has designed a survey to measure AHTO in order to facilitate international comparisons ${ }^{40}{ }^{41}$ but unfortunately authors were not aware of this when they began the current study. While lengthy, using this would be a good way to develop a comprehensive and consistent evidence base. However, it is clear that there are differences across harm types and more detailed analysis of specific harms would be valuable for supporting remedial action from policy-makers. Here, we consider 'aggressive harms' as a distinctive group of harms; future research could consider other harm groupings in order to provide a more detailed assessment of specific harm types. Research on the types of alcohol consumption patterns that increase the likelihood of experiencing AHTO in the UK would be valuable. Understanding what puts younger adults at increased risk could be a useful focus for future research as it might identify the contextual factors which make experiencing harm more likely. Further focus on the differences in harm by sex would also be advantageous as there is little data on this in relation to the UK. Policy to address AHTO is less well developed than policy that seeks to address harms to the drinker; exceptions include crime and violence and harm to the unborn fetus which have been included in previous Government's Alcohol Strategy. ${ }^{42}$ Given that AHTO research is in its early stages, it is too early to advocate a detailed policy response but results presented here will be of interest to policy-makers to help understand the wider impact of other people's drinking.

Acknowledgements The authors would like to thank the alcohol expert forum of the Five Nations Public Health Peer Network for initiating this work and to PHE for funding it. Thanks also to the following people in PHE: Craig Timpson for quality assuring the analyses, Helen Outhwaite for help with searching for literature, Robyn Burton and Helen Willey for their input into early conversations about methods and Fionnuala 0'Toole and Alyson Jones for proofreading/editing the paper. Thanks to Dr Jamie Brown, University College London, for permitting the harm to others questions to be appended to the ATS and for his subsequent support with interpretation of the alcohol toolkit survey questions. Thanks to Ipsos MORI for delivering the survey, in particular Stuart Smedley. Finally, thanks to the four reviewers for their comments on this paper.

Contributors CB provided day-to-day management of the study, helped design the questionnaire and wrote the first draft. DB did the analysis and helped to write the first draft. JM undertook a review of the literature. KS was involved with the initiation, helped design the questionnaire and provided statistical support. CP was involved with the initiation of the study. $\mathrm{CH}$ was involved with the initiation of the study and helped design the questionnaire. All authors reviewed and helped to revise successive drafts and approved the final version of the manuscript.

Funding The work was funded by Public Health England.

Competing interests None declared.

Patient consent for publication Not required.

Ethics approval Approval for the ATS was granted by University College London's ethics committee (reference: 0498/001) and for the AHTO questions by the Research Support and Governance Office, Public Health England (reference: R\&D 055).

Provenance and peer review Not commissioned; externally peer reviewed.

Data sharing statement Sharing of data will be considered by PHE and UCL on a case-by-case basis. Please contact the lead author for further details.

Open access This is an open access article distributed in accordance with the Creative Commons Attribution Non Commercial (CC BY-NC 4.0) license, which permits others to distribute, remix, adapt, build upon this work non-commercially, and license their derivative works on different terms, provided the original work is properly cited, appropriate credit is given, any changes made indicated, and the use is non-commercial. See: http://creativecommons.org/licenses/by-nc/4.0/.

\section{REFERENCES}

1. World Health Organization. Global status report on alcohol and health. Geneva: World Health Organization, 2014.

2. World Health Organization. Global strategy to reduce the harmful use of alcohol. Geneva: World Health Organization, 2010.

3. Office for National Statistics. Chapter 5: violent crime and sexual offences - alcohol-related violence. London: Office for National Statistics, 2015.

4. Bellis MA, Quigg Z, Hughes K, et al. Harms from other people's drinking: an international survey of their occurrence, impacts on feeling safe and legislation relating to their control. BMJ Open 2015;5:e010112.

5. Moan IS, Storvoll EE, Sundin E, et al. Experienced harm from other people's drinking: a compar ison of Northern European Countries. Subst Abuse 2015;9:45-57.

6. Storvoll EE, Moan IS, Lund IO. Negative consequences of other people's drinking: prevalence, perpetrators and locations. Drug Alcohol Rev 2016;35:755-62.

7. Ramstedt M, Sundin E, Moan IS, et al. Harm experienced from the heavy drinking of family and friends in the general population: a comparative study of Six Northern European Countries. Subst Abuse 2015;9(Suppl 2):SART.S23746. 
8. Burton $\mathrm{R}$, Henn $\mathrm{C}$, Lavoie $\mathrm{D}$, et al. A rapid evidence review of the effectiveness and cost-effectiveness of alcohol control policies: an English perspective. The Lancet 2017;389:1558-80.

9. Hope A, Curran J, Bell G, et al; Unrecognised and under-reported: the impact of alcohol on people other than the drinker in Scotland. Glasgow: Alcohol Focus Scotland, 2013.

10. Quigg Z, Bellis AM, Grey H, et al. Alcohol's harms to others: the harms from other people's alcohol consumption in Wales. Public Health Wales: Cardiff, 2016.

11. Hope A. Alcohol's harm to others in Ireland. Dublin: Health Service Executive, 2014.

12. Beard E, Brown J, West R, et al. Protocol for a national monthly survey of alcohol use in England with 6-month follow- up: 'the Alcohol Toolkit Study'. BMC Public Health 2015;15:230.

13. Gell L, Ally A, Buykx P, et al. Alcohols harm to others. Sheffield: The University of Sheffield, 2015.

14. Barbor T, Higgins-Biddle J, Saunders J, et al; AUDIT: The alcohol use disorders identification test, guidelines for use in primary care. 2nd edn. Geneva: World Health Organization, 2001.

15. StataCorp. Stata survey data reference manual: release 13. Texas: StataCorp LP, 2013.

16. Rao JNK, Scott AJ. On Chi-Squared Tests for Multiway Contingency Tables with Cell Proportions Estimated from Survey Data. The Annals of Statistics 1984;12:46-60.

17. Johnson TP. Sources of Error in Substance Use Prevalence Surveys. Int Sch Res Notices 2014:2014:1-21.

18. Office for National Statistics. Estimates of violent incidents where the victim believed the offender(s) to be under the influence of alcohlol or drugs in England and Wales, year ending March 2006 to year ending March 2016 Crime Survey for England and Wales, 2017.

19. Greenfield TK, Midanik LT, Rogers JD. Effects of telephone versus face-to-face interview modes on reports of alcohol consumption. Addiction 2000;95:277-84.

20. Greenfield TK, Ye Y, Kerr W, et al. Externalities from alcohol consumption in the 2005 US National Alcohol Survey: implications for policy. Int J Environ Res Public Health 2009;6:3205-24.

21. Stanesby O, Rankin G, Callinan S. Experience of harm from others' drinking and support for stricter alcohol policies: Analysis of the Australian National Drug Strategy Household Survey. Int J Drug Policy 2017:45:25-32.

22. Ferris J, Devaney M, Davis G, et al. Reporting of problematic drinkers and the harm they cause: assessing the role of alcohol use, sex, and age of those affected by a problematic drinker. Exp Clin Psychopharmacol 2016;24:48-54.

23. Karriker-Jaffe KJ, Greenfield TK. Gender differences in associations of neighbourhood disadvantage with alcohol's harms to others: a cross-sectional study from the USA. Drug Alcohol Rev 2014;33:296-303.

24. Greenfield TK, Karriker-Jaffe KJ, Kaplan LM, et al. Trends in Alcohol's Harms to Others (AHTO) and Co -occurrence of Family -Related AHTO: The Four US National Alcohol Surveys, 2000-2015. Subst Abuse 2015;9(Suppl 2):SART.S23505-31.
25. Hurcombe R, Bayley M, Goodman A. Ethnicity and alcohol: a review of the UK literature. Joseph Rowntree Foundation: York, 2010.

26. Hughes K, Bellis MA, Jones L, et al. Prevalence and risk of violence against adults with disabilities: a systematic review and metaanalysis of observational studies. The Lancet 2012;379:1621-9.

27. Krnjacki L, Emerson E, Llewellyn G, et al. Prevalence and risk of violence against people with and without disabilities: findings from an Australian population-based study. Aust N Z J Public Health 2016;40:16-21.

28. Frier A, Barnett F, Devine S, et al. Understanding disability and the 'social determinants of health': how does disability affect peoples' social determinants of health? Disabil Rehabil 2018:40:538-47.

29. Seid AK, Grittner U, Greenfield TK, et al. To cause harm and to be harmed by others: new perspectives on alcohol's harms to Others. Subst Abuse 2015;9:13-22.

30. Lewis-Laietmark C, Wettlaufer A, Shield KD, et al. The effects of alcohol-related harms to others on self-perceived mental well-being in a Canadian sample. Int J Public Health 2017;62:669-78.

31. Kushel MB, Evans JL, Perry S, et al. No door to lock: victimization among homeless and marginally housed persons. Arch Intern Med 2003;163:2492-9.

32. Nyamathi AM, Leake B, Gelberg L. Sheltered versus nonsheltered homeless women differences in health, behavior, victimization, and utilization of care. J Gen Intern Med 2000;15:565-72.

33. Farrall S, Hay C, Jennings W, Gray E, et al. Thatcherite ideology, housing tenure and crime: the socio-spatial consequences of the right to buy for domestic property crime. Br J Criminol 2016;56:1235-52.

34. Office for National Statistics. Adult drinking habits in Great Britain: 2017. Newport: Office for National Statistics, 2018

35. Office for National Statistics. Overview of violent crime and sexual offences. Newport: Office for National Statistics, 2016.

36. Kaplan LM, Karriker-Jaffe KJ, Greenfield TK. Drinking context and alcohol's harm from others among men and women in the 2010 US National Alcohol Survey. J Subst Use 2017;22:412-8.

37. Casswell S, You RQ, Huckle T. Alcohol's harm to others: reduced wellbeing and health status for those with heavy drinkers in their lives. Addiction 2011;106:1087-94.

38. Jiang $\mathrm{H}$, Callinan $\mathrm{S}$, Laslett AM, et al. Correlates of caring for the drinkers and others among those harmed by another's drinking. Drug Alcohol Rev 2015;34:162-9.

39. Muzet A. Environmental noise, sleep and health. Sleep Med Rev 2007;11:135-42.

40. World Health Organization/ThaiHealth International Collaboration Research Project. The harm to others from drinking. Geneva: World Health Organization, 2012.

41. Callinan S, Laslett A-M, Rekve D, et al. Alcohol's harm to others: an international collaborative project. Int $J$ Alcohol Drug Res 2016:5:25-32.

42. HM Government. The government's alcohol strategy. London: HM Government, 2012. 